\title{
RELATO DE
}

EXPERIÊ NCIA

\section{O BRINCAR COMO INTERVENÇÃO E PROMOÇÃO DE SAÚDE NO TRABALHO COM EDUCADORAS INFANTIS}

DOI: 10.22289/2446-922X.V6N2A8

\author{
Gema Galgani da Fonseca ${ }^{1}$ \\ Karla Cristina da Silva
}

\section{RESUMO}

A sociedade ainda possui uma visão limitada e mal compreendida sobre o trabalho do educador, o que contribui para que os mesmos se sintam desmotivados e desvalorizados. É notável o crescimento de adoecimentos relacionados ao trabalho no contexto da educação infantil devido as condições laborais existentes como: as creches superlotadas, as famílias que se ausentam da responsabilidade do cuidado dos filhos e não reconhecem o trabalho do educador e etc. Todos esses motivos atrelados a subjetividade de cada educador e seus recursos internos de encontrarem escoadores para o não adoecimento físico e emocional, corroboram para desencadear níveis de esgotamento cada vez maiores no ambiente de trabalho. As participantes foram oito educadoras do Centro Educacional Municipal Infantil (CMEI) Vovó Chiquinha, da Prefeitura Municipal de Patos de Minas. Sendo os encontros realizados quinzenalmente no período de uma hora. O projeto teve como objetivo oportunizar a abertura e espaço adequado para que as educadoras aprendessem a lidar e amenizar os fatores de estresse no ambiente de trabalho, de maneira prazerosa - lúdica e com possiblidades de dar novos sentidos as práticas profissionais. A metodologia utilizada foi o brincar como estratégia, intervenção e promoção de saúde no trabalho para as professoras da Educação Infantil. Com a realização do projeto possibilitou maior compreensão e respeito entre as educadoras e melhorias nas relações interpessoais e no ambiente de trabalho.

Palavras-chave: Professoras; Trabalho; Jogos; Saúde Psicoemocional.

\section{PLAYING AS A FORM OF INTERVENTION AND HEALTH PROMOTION IN THE WORK WITH CHILD EDUCATORS}

\begin{abstract}
Society still has a limited and poorly understood view of the educator's work, which contributes to their feeling unmotivated and undervalued. It is remarkable the growth of work-related illnesses in the context of early childhood education due to existing working conditions such as overcrowded day care centers, families who are absent the responsibility of childcare and do not recognize the work of the educator and so on. All these reasons linked to the subjectivity of each educator and their internal resources to find outlets for physical and emotional non-illness corroborate to trigger increasing levels of enxhaustion in the workplace. The participants were eight educators from the Vovó Chiquinha Municipal Children's Educational Center (CMEI), from the Patos de Minas City
\end{abstract}

${ }^{1}$ Endereço eletrônico de contato: ggalgani.fonseca@gmail.com

Recebido em 11/11/2019. Aprovado pelo conselho editorial para publicação em 10/03/2020. 
Hall. The meetings are held fortnightly within one hour. The project aimed to provide the opening and adequate space for educators to learn to deal with and mitigate stressors in the workplace, in a pleasurable - playful way and with the possibility of giving new meanings to professional practices. The methodology used was play as a strategy, intervention and health promotion at work for teachers of early childhood education. With the completion of the project, it enabled greater understanding and respect among the educators and improvements in interpersonal relationships and in the workplace.

Keywords: Teachers; Job; Games; Psycho-Emotional Health.

\section{EL JUEGO COMO INTERVENCIÓN Y PROMOCIÓN DE LA SALUD EN EL TRABAJO CON EDUCADORES INFANTILES}

\section{RESUMEN}

La sociedad todavía tiene una visión limitada y poco entendida del trabajo del educador, lo que contribuye a que se sienta desmotivado y devaluado. Se destaca el crecimiento de enfermedades relacionadas con el trabajo en el contexto de la educación infantil debido a las condiciones laborales existentes como: guarderías superpobladas, familias ausentes de la responsabilidad del cuidado de sus hijos y que no reconocen la labor del educador, etc. Todas estas razones, ligadas a la subjetividad de cada educador y sus recursos internos para encontrar salidas a la no enfermedad física y emocional, corroboran para desencadenar niveles crecientes de agotamiento en el ámbito laboral. Los participantes fueron ocho educadores del Centro Educativo Infantil Municipal Vovó Chiquinha (CMEI), del Municipio de Patos de Minas. Las reuniones se llevan a cabo cada dos semanas en una hora. El proyecto tuvo como objetivo brindar una apertura y un espacio adecuado para que los educadores aprendan a lidiar y aliviar los factores estresantes en el entorno laboral, de una forma amena - lúdica y con la posibilidad de dar nuevos significados a las prácticas profesionales. La metodología utilizada fue el juego como estrategia, intervención y promoción de la salud en el trabajo para docentes de Educación Infantil. Con la realización del proyecto, permitió una mayor comprensión y respeto entre los educadores y mejoras en las relaciones interpersonales y en el ambiente laboral.

Palabras Ilave: Docentes; Trabajo; Juegos; Salud Psicoemocional.

\section{INTRODUÇÃO}

A necessidade em atender crianças em creches surgiu em meados do século XIX, devido ao espaço no mercado de trabalho conquistado pelas mulheres, inicialmente atendendo de maneira assistencial a famílias pobres e relacionada a órgãos governamentais. A princípio o atendimento era de assistencialismo e cuidado, com o passar dos anos, a prática foi se formalizando e foi entendendo que era necessário um trabalho além do assistencial. Uma prática educacional alinhada ao cuidado se instala (Alencar \& Oliveira, 2017).

De acordo Malvestiti, Maas e Gontijo (2017) com este novo modelo quem recebe a tarefa de cuidar e educar, são profissionais formados em pedagogia. O educador infantil possuí muitos encargos, é ele, junto com a família o responsável pela alimentação adequada, higiene, ensinar conteúdos pertinentes para a idade e observar o desenvolvimento da criança.

Rev. Psicol Saúde e Debate. Set., 2020:6(2): 118-134. 
Neste momento o jogo e a brincadeira tornam-se o principal instrumento de ensino no processo de aprendizagem nos Centros Educacionais Infantis (Alencar \& Oliveira, 2017). Para Kishimoto (2017) o brincar recebe várias tipologias, uma vez que pode ser uma brincadeira livre ou dirigida de forma pedagógica. O brincar livre implica prazer e desprazer, em que a criança tem a oportunidade de criar, imaginar e expressar. E o brincar educativo, é o que agrega no ensinoaprendizagem e no seu desenvolvimento como um todo; físico, cognitivo, emocional e até mesmo social.

O educador entre suas habilidades e responsabilidades deve participar do brincar com a criança, pois somente assim conseguir-se-á acessar o mundo infantil e implementar trabalhos pedagógicos eficazes. Para os autores Santos e Cruz (1997) é importante que o adulto vivencie a ludicidade, sendo assim sua probabilidade de trabalhar de forma prazerosa com crianças será maior.

Freire e Garcia (2011) confirmam que o retorno à brincadeira na fase adulta auxilia a pessoa na capacidade de agir sobre a situação que está vivenciando, uma vez que o brincar ajuda no desenvolvimento de habilidades, criatividade, expressão de sentimentos e resolução de problemas e conflitos. O que pode também despertar e gerar uma gama de sentimentos e reminiscências aos adultos, como nas educadoras da Educação Infantil.

Freud (1908 [1907]) afirma que o trabalho exige aspectos vivenciados na infância e principalmente do brincar, uma vez que o trabalho é uma substituição do brincar infantil. Ou seja, através das formas que o adulto apreende e se apropria de seu trabalho, traduz-se muitas películas da criança que foi.

O trabalho além de uma fonte de renda é gerador de prazer, realização, subjetividade e dignidade humana, porém também pode ocasionar sofrimento e conflitos. Para Dejours (1987) o trabalho causa impacto no aparelho psíquico, podendo surgir adoecimentos ao defrontar-se a vida pessoal com desejos e projetos e o que a organização espera.

A educação infantil possui grande importância para o desenvolvimento da criança, porém, necessita de muito preparo, atenção, cuidado, observação e comunicação. Exigindo assim do educador uma grande disposição física, e psicoemocional, e, que por vezes acabam por aumentar os níveis de estresse e possibilidades de adoecimentos orgânicos e psicossomáticos.

O brincar como intervenção e promoção de saúde no trabalho se mostra um instrumento eficiente e importante para ser trabalhado com adultos (Freire \& Garcia, 2011). Daí, nossa motivação e recorte temático para a dimensão do "Brincar no trabalho junto às educadoras", as quais cuidam e brincam com tantos seres em formação; e quem brinca e cuida delas em seu universo?

Diante do mencionado o trabalho teve como objetivo utilizar o brincar como estratégia, intervenção e promoção de saúde no trabalho para as professoras da Educação Infantil, mobilizando o autoconhecimento, o valor pessoal, relacionamentos no trabalho, por meio da Rev. Psicol Saúde e Debate. Set., 2020:6(2): 118-134. 
ludicidade dar possibilidades de escoadores de adoecimentos, físico e psicoemocional; minimizando também indicadores psicossomáticos e potencializar fatores de proteção.

\section{MATERIAIS E MÉTODOS}

Este relato de experiência faz parte de um projeto interdisciplinar MIP (Mostra Interdisciplinar Profissional) da Faculdade Patos de Minas realizado com oito professoras da educação infantil de um Centro Educacional Municipal Infantil (CMEI) da Prefeitura Municipal de Patos de Minas. Foram realizados dez encontros que aconteceram quinzenalmente no período de uma hora, tendo como proposta Oficinas Temáticas e Psicopedagógicas (debates, dinâmicas, jogos, vivências, atividades artísticas, etc.), sempre alinhadas às atividades lúdicas. Os mesmos foram realizados por três estudantes - estagiárias de psicologia da faculdade citada acima.

Os encontros ocorreram no CMEI em sala separada (brinquedoteca dos alunos), já que estes tiveram como proposta contribuir para a melhoria da dimensão escolar e da sua equipe. Com o intuito de amenizar adoecimentos e intervir de maneira leve e descontraída em meio as angústias e frustrações das professoras, foi levado em consideração os múltiplos contextos e suas práticas diárias; promovendo e mobilizando estratégias para melhor trato com as demandas escolares e trabalho coletivo.

Primeiramente foi levado a nossa orientadora várias motivações - ideias e desejos para o trabalho, a qual nos auxiliou a definir a proposta de trabalho centrando o olhar sobre às educadoras. Logo após formulamos o projeto e encaminhamos a coordenação do curso de Psicologia para Aprovação, quando liberado foi encaminhado também para a coordenadora do CMEI para seu conhecimento e validação. Nesse momento pode-se perceber o interesse e disponibilidade especial de algumas educadoras com a proposta a ser desenvolvida, se mostrando sentirem valorizadas ao olhar para elas.

No primeiro encontro apresentamos ao grupo de educadoras nossa proposta e demos início ao projeto, quando foi evidente uma gama de sentimentos e emoções múltiplas como; interesse, satisfação, insegurança, resistência, etc. Entre os dez encontros realizados desenvolveu-se os seguintes temas: identidade, comunicação, trabalho em grupo, empatia, emoções, percepção do outro, frustrações, crescimento profissional, afeto e interação do trabalho. E no último encontro foi realizado uma linha do tempo com todos os temas trabalhados durante o projeto e feedback do mesmo, quando se evidenciou respostas prospectivas sobre aprendizados e crescimentos partilhados e construídos com o grupo.

Os encontros tinham como proposta um eixo norteador através da temática definida conforme demandas suscitadas no grupo, bem como, compromisso de dar seguimento ao anterior. A cada encontro realizado relatávamos e analisávamos junto a orientadora, o que havia 
ocorrido na realização do trabalho e levávamos a próxima proposta, a qual nos orientava e direcionava sobre qual a melhor forma de abordar os temas e quais metodologias mais adequadas.

Posteriormente ao término da execução do projeto com as educadoras, realizamos a apresentação de todo trabalho desenvolvido em uma semana acadêmica na faculdade Patos de Minas destinada especificamente, a estes fins, sendo compartilhado a apresentação junto com vários outros projetos de intervenção - MIP, e contou com uma banca de avaliação.

\section{RELATO DA EXPERIENCIA}

As professoras chegaram e ficaram livres para escolher seus lugares dentro da sala e quando todas estavam presentes, explicamos o objetivo do projeto e as atividades que iriamos desenvolver por meio deste. Percebeu-se dentre as reações iniciais uma insegurança por ser algo novo e ao mesmo tempo muitas expectativas foram levantadas a respeito do projeto.

No primeiro encontro, o tema trabalhado foi a "Identidade Docente" porque percebeu-se angustias e motivações por parte das mesmas, quando se utilizou para a realização da atividade os materiais; uma boneca e uma trouxinha com trechos de um poema de Shakespeare: Eu aprendi. Teve-se como finalidade a promoção de uma auto apresentação das professoras participantes de uma forma descontraída e com liberdade de expressão.

No início do trabalho e já inserindo o lúdico na dinâmica, foi proposta a utilização da boneca como objeto de representação do EU, solicitando que as mesmas se apresentassem e relatassem sobre sua profissão; como foi construído o processo de ser educadora, sonhos, desejos, desafios e talentos desenvolvidos. Foi entregue a primeira participante a boneca, que após a apresentação individual foi passada para as outras educadoras no decorrer da atividade.

Pode-se observar uma semelhança no relato das professoras, sobre questões como; muitas delas não sonhavam em ser educadoras, a maioria começou na profissão por questões financeiras, outras por vontade da família ou por seguir os passos da mãe. Bem como, dentre uma das maiores dificuldades vivenciadas no trabalho de educadora foi destacado que; conversar com os pais diante de uma criança que caiu ou que foi mordida ou mordeu outra criança. E que atualmente a maior dificuldade está em deixar os problemas escolares na escola.

Apesar de muitas não escolherem a profissão, seguiram na carreira pois criou-se gosto pelo trabalho exercido. Houve também relatos sobre a possibilidade de fazer o curso dos sonhos e de não permanecer por muito tempo na atual profissão. E ainda, foram levantados temas importantes a serem discutidos no ambiente de trabalho e que auxiliou na definição do tema do segundo encontro, uma das habilidades sociais: a comunicação. 
No segundo encontro conforme mencionado o tema comunicação foi levado a reflexão e discussão, propondo que cada participante pegasse uma estrofe do poema escolhido - para ser ouvido (autor desconhecido) e posto que ficassem livres para lê-los ou não; sendo que as oito educadoras leram e comentaram sobre os insights tidos. Foi observado que nesse momento elas estavam mais relaxadas e descontraídas e assim na segunda rodada foi dada a opção de dar a frase para outra educadora; evidenciando que todas as participantes leram e muitas guardaram a frase para si, duas dividiram a frase com as estagiárias mesmo falando que não estavam participando.

Posteriormente foi informado às educadoras que poderiam levar as respectivas frases para casa e realizamos uma dinâmica do telefone sem fio, quando as mesmas ficaram em filas e a primeira educadora recebeu a seguinte frase digitada em um papel: EU AMO MINHA CRIANÇA INTERIOR e precisou repassar esta frase apenas com gestos a outra colega e assim sucessivamente. No final foi perguntado a última pessoa o que ela entendeu daquele gesto e 0 que seria a frase.

As educadoras relataram muita dificuldade em passar adiante a mensagem e que no final entenderam de forma distorcida, mas com sentido parecido; quando retomamos. que foi dito no encontro anterior por elas: sobre as dificuldades de comunicação com os pais das crianças. Articulando a reflexão com o contexto do trabalho, as diversas maneiras de comunicação e também com a proposta do projeto, foi enfatizado que um ambiente com boa comunicação se estabelece como fator de proteção aos adoecimentos e/ou conflitos, gerador de saúde.

Foi destacado com elas que, se ocorre a abertura para a comunicação sincera e necessária, evita-se mágoas... ressentimentos... frustrações; as quais muitas das vezes potencializam outros entraves e a partir dessa reflexão também se evidenciou a importância de se trabalhar em grupo. Assim, a unidade foi um ponto observado que necessitava ser trabalhado e escolhido para ser explorado no terceiro encontro, com a nomeação do tema: o EU COLETIVO.

O terceiro encontro foi iniciado com a explicação do tema, o EU COLETIVO; o qual se pautou no contexto cultural da escola - na formação e história profissional de cada educadora, o perfil e condição laboral das mesmas na atualidade, dentre outros. Os materiais para a dinâmica foram colocados em cima da mesa para as educadoras escolherem e explorar sua criatividade para responder aos direcionamentos abaixo por meio de; pinturas, desenhos, ilustrações, palavras, frases, com as canetinhas coloridas, tintas e representações no papel pardo.

1- Como é a instituição e quais os conhecimentos que temos sobre ela? (O que a instituição espera de cada educadora, quais os valores e cultura, quais as expectativas de cada educadora na instituição).

1- Como as educadoras tem agido na instituição? (o lidar com a demanda educacional da instituição, o lidar com o trabalho coletivo e o outro). 
2- $\quad$ O que pode ser melhorado dentro do contexto ao qual se encontram? (o que pode ser mudado coletivamente e que implicará em um melhor ambiente de trabalho).

As educadoras tiveram dificuldades para responder as questões e algumas resistiram em certo tempo para colocarem suas opiniões no papel. Após atividade ter sido concluída foram colocados os três papéis no chão e questionado o que cada educadora quis expressar por meio das ilustrações e palavras. O que predominou foi o respeito pelo outro, em que foram levantadas questões como: é mais fácil falar do respeito do que colocá-lo em prática, e principalmente a necessidade da empatia e capacidade de se colocar no lugar da outra.

Em relação ao respeito relataram situações em que as educadoras são julgadas no ambiente de trabalho por realizarem boas ações, como por exemplo; as vezes que precisam de ajuda, mas não recebem, a falta de respeito que está presente, mas não de forma tão explícita. Reiteraram sobre a importância da comunicação que foi o tema trabalhado no encontro anterior, acrescentando sobre a necessidade de terem e desenvolver a empatia, justificando que sem ela não é possível se relacionar com o outro e principalmente como EU COLETIVO.

A proposta dessa atividade foi levar as participantes a uma reflexão sobre o EU COLETIVO neste contexto de trabalho: o que se conhece da instituição, o que é esperado pela instituição e por elas, quais os valores e culturas presentes, como está o trabalhar coletivo e a relação com as colegas de trabalho, quais os pontos que necessitam de melhorias, e quais as contribuições que cada uma pode dar ao grupo.

Conclui-se que estes pontos, quando levantados numa discussão, podem melhorar e aumentar a qualidade e saúde do trabalhador neste ambiente. Sendo percebido e endossado, que quando as educadoras se juntam, se forma uma equipe e torna-se um EU COLETIVO, em busca de objetivos e realizações em comum. O encerramento se deu por meio de um vídeo sobre a importância de se trabalhar em equipe - A importância do trabalho em equipe para o sucesso.

No quarto encontro, para dar continuidade as falas das educadoras em relação ao tema anterior, quando foram levantadas reflexões sobre se colocar no lugar do outro, escolheu-se para este o tema EMPATIA. Ao chegarem na sala estava passando a música Caribbean Blue da cantora Enya, momento que foi dito que o encontro daquele dia já havia se iniciado e pedido que elas ouvissem e sentissem a música. Após o término da música perguntamos o que elas sentiram e o que foi despertado. A educadora 1 disse que sentiu vontade de receber uma massagem, dormir, as outras disseram que sentiram sono também e que as fizeram pensar.

Foi pedido então, para que voltassem a atenção ao cartaz que estava na porta com a seguinte frase:

Não é sentir pelo outro, mas sentir com o outro.

Quando a gente lê o roteiro de outra vida.

É ser ator em outro palco. É compreender.

Rev. Psicol Saúde e Debate. Set., 2020:6(2): 118-134. 
É não dizer "eu sei como você se sente".

É quando a gente não diminui a dor do outro.

É descer até ao fundo do poço e fazer companhia pra quem precisa.

Não é ser herói, é ser amigo.

É saber abraçar a alma.

João Doederlein

Neste momento foi lido em voz alta e explicado que o tema do encontro - a capacidade de se colocar no lugar do outro, quando foi entregue a elas a boneca de EVA com um post it colado, e solicitado para que as mesmas escrevessem algum problema que as inquietavam, de forma que ninguém reconhecesse a escrita uma das outras. E assim foi feito, foram recolhidos os papeizinhos, colocados em uma caixinha para misturá-los e distribuí-los de forma aleatória. Logo após cada educadora com o problema do outro em mãos pensaria em uma solução.

Cada educadora com seu devido problema buscou formas de amenizar e solucionar aquele problema, porém foi percebido que algumas não consideravam o problema do outro um problema, ou não conseguiram compreender onde estava a dificuldade. Outras apresentaram algumas soluções como: conversar mais com a equipe e falar o que se busca, se comunicar. Quando indagadas se o problema que foi escrito por elas, foi compreendido; a resposta unânime foi que não, e quando questionadas sobre seus sentimentos, trouxeram que sentiram incompreendidas.

Voltou-se a atenção novamente ao cartaz, elas mesmas quiseram falar de partes do poema que condiziam com que elas sentiram e com o tema do encontro, momento pelo qual cada uma se manifestou dizendo sobre essa capacidade de olhar o outro e de como o problema do outro sempre é percebido como menor. Concluindo-se que o que se pode fazer é apoiar e tentar ajudar no que for possível, mas a dor do outro é o outro que está sentindo e somente ele - com amparo ou sozinho poderá lidar.

Nesta hora elas expressaram a falta de compreensão com o problema uma das outras e que as vezes não conseguem sentir o mesmo, mas que tentariam ficar juntas. $O$ encontro foi finalizado com este espaço de reflexão e foi dito a elas que a boneca poderia ser levada para casa e poderia ser personalizada da forma que quisessem; colar roupas cabelos, acessórios, sapatos e também precisariam alimentá-la, com emoções, segredos, vivências, sonhos... E que posteriormente seria trabalhado com a boneca novamente.

No quinto encontro o tema abordado foi sobre as emoções devido essas inquietações em atividade anterior ter suscitado as mesmas. Foi solicitado às educadoras assim que chegaram, que escrevessem em um papel emoções e sentimentos predominantes e quais os efeitos físicos que ocasionavam, sendo que algumas tiveram dificuldades e uma delas em particular apenas Rev. Psicol Saúde e Debate. Set., 2020:6(2): 118-134. 
realizou desenhos na folha. Mas de modo geral, conseguiram passar para o papel emoções e sensações físicas conforme proposto e prevalecendo o respeito a forma e condição de expressão de cada uma delas.

Foi pedido então, para que cada uma lesse em voz alta o que tinham escrito no papel e depois perguntado o que demorava mais a desaparecer; se era a sensação física ou as emoções. $\mathrm{O}$ que todas chegaram à conclusão que resolvendo o emocional, o sintoma físico vai embora como consequência. Logo após foram convidadas para que uma a uma se direcionassem a lixeira e fossem jogando os sentimentos e emoções ruins fora, e dissessem o pôr que do descarte dessas emoções. A educadora 1 se prontificou a iniciar, esta sempre foi muito aberta as vivências do projeto, disse a emoção que não precisava que seria a mágoa e rasgou o papel.

A educadora 2 que teve dificuldades em jogar o ruim fora, se justificando que se jogasse isso fora estaria desmerecendo ou dando pouca importância a mágoa ou ao mal que a pessoa a causou. Inclusive deu um exemplo de infância em que sofreu bullying e que até hoje quando vê a pessoa ainda se lembra de forma muito vívida. Por isso, disse ser difícil jogar tudo isso no lixo, devido ao apego ao que sofria e disse precisar de terapia.

A educadora 3 preferiu não revelar o que escreveu (sempre muito resistente).

A educadora 4 emocionada, ficou com os olhos marejados ao falar da insegurança que queria jogar fora e de como a criação influenciou e influencia hoje. Rasgou bem e embolou tudo antes, como muita vontade de descartar tudo.

A educadora 5 cheia de emoções e sintomas físicos, como: dores no estômago, dores de cabeça, diarreia, falou do medo de tudo que surgiu na infância e do tanto que precisava vencer esse entrave.

A educadora 6 também falou sobre seus medos.

E a $7^{\text {a }}$ educadora jogou seus sentimentos escritos no papel, no lixo.

Realizou-se o fechamento entregando a elas o texto: Lei do caminhão de lixo, para levarem para casa, enfatizando que quando não se fala dos sentimentos, acaba-se por internalizá-los, de modo a causar danos à saúde psíquica e correndo o risco de adoecer e entrar em conflito nas relações interpessoais. No ambiente de trabalho, leva-se tudo que está de bom e o que não está, quando foi retratado sobre a necessidade de reconhecer o que se está sentindo, falar sobre e tentar lidar com esses sentimentos. Sendo posto, que quanto mais alimentá-los, maiores ficam internamente e mais difícil se torna para suportar, o que pode ocasionar desequilíbrios emocionais e reiterado o contrapondo disso, a pratica de jogar no lixo, os maus sentimentos.

O sexto encontro foi iniciado falando sobre o tema do encontro - O que você parece para mim, e logo depois foi pedido para que cada uma escolhesse uma canetinha que estava em cima da mesa e foi colado a folha sulfite em branco com fita crepe nas costas de cada uma. As mesmas teriam que escrever qualidades que possuíam ou que admiravam ou que a colega Rev. Psicol Saúde e Debate. Set., 2020:6(2): 118-134. 
possuía na folha uma das outras, de forma que todas escrevessem em todas. Ao final ainda com as folhas nas costas, foi pedido para que se sentassem e indagado se sabiam sobre o que estava escrito, quando relataram que elas tinham alguma ideia, porém era mais fácil enumerar seus defeitos que suas qualidades.

A educadora 2 disse que sempre foca no positivo, elogia muito porque também gosta de ser elogiada.

Então foi dado um espaço para que elas olhassem as qualidades da folha, pois já estavam ansiosas e muitas se surpreenderam, disseram que não tinha ideia que aquela qualidade pertencia a elas. Foi aberto um tempo cada uma falar de suas qualidades e se eram essas qualidades que elas imaginavam ler.

Segue abaixo algumas falas:

-Ah eu também sou amiga, sou mais fechada mais sou amiga também, podem contar comigo! (Educadora 3).

-Eu não sou paciente e nem calma, como vocês veem isso em mim? (Educadora 1)

Todas ficaram muito contentes em perceber a quantidade de qualidades que foram enumeradas pelas colegas, sendo evidenciado que as vezes se foca somente nos defeitos e acaba que as qualidades passam despercebidas e que era isso que fazia a equipe funcionar, que cada uma tem algo especial.

Foi falado um pouco sobre a importância de se destacar as qualidades e potencialidades do outro, as quais podem ser fatores motivadores para o trabalho e geradores de saúde; atitudes que podem melhorar o ambiente, o próprio lar e o cotidiano de vida.

O sétimo encontro teve como tema - Frustrações, o qual foi marcante para as estagiárias de psicologia e para as educadoras, pois este foi iniciado com alguns recipientes de tomar sorvete na mesa com colheres e perguntado a elas se estavam com calor naquele dia, e a resposta foi que sim. Então elas questionaram se teria um sorvete para elas e começaram a ficar contentes.

Um pote de sorvete sem a identificação da embalagem e que estava na geladeira, foi entregue a elas, quando começaram a indagarem se aquilo não seria feijão, um mousse, um doce? Foi pedido para que uma das educadoras se levantasse e nos ajudasse a distribuir as vasilhas para distribuir o sorvete, e quando a primeira participante foi se servir; lá estava um pote cheio de feijão.

Elas começaram a nomear o que estavam sentindo: decepção, uma brincadeira sem graça e por último FRUSTRAÇÃO, e então a partir daí o tema daquele encontro foi relatado, e que seria a frustração no trabalho. Que muitas vezes se espera algo e encontra com outra coisa completamente diferente, surgindo a frustração. Foi feito uma relação do tema ao ambiente de trabalho e solicitado para que elas pensassem em uma situação ou mais que as deixavam 
frustradas, e que em grupo fizessem um pequeno teatro representando estas frustrações cotidianas, tudo dentro de 15 minutos e que poderiam utilizar dos materiais que havíamos levado.

As educadoras foram deixadas na sala à vontade, sem a presença das estagiárias. E do lado de fora era possível ouvir a euforia e entusiasmo que conversavam e se organizavam para fazer o teatro. Faltando apenas 3 minutos elas abriram a porta e convidaram as estagiárias a entrar. $\mathrm{Na}$ sala as mesmas haviam deixado três cadeiras para que se sentassem e as assistissem, e começaram o teatro.

Sentadas no chão com alguns brinquedos, cinco das educadoras brincavam, brigavam e mordiam. A educadora 3 representava uma estagiária de pedagogia com o celular na mão, mal conseguia falar com as crianças e colocar a sala em ordem. A educadora 1 teve como papel a educadora em sala de aula e chega para dar o que tinha planejado, com um vestido de princesa e uma peruca branca, tenta contar a história mas a sala está de pernas para ar, as crianças se batem, se mordem, levantam, não fazem silêncio e não obedecem. A professora desiste de dar o planejado, se levanta e diz que a história acabou. A educadora 3 representando um dos pais chegando na escola, começa a questionar a bagunça da sala, as crianças começam a chorar, a mãe pergunta quem mordeu o filho; maltrata a educadora e assim termina a encenação.

Tudo aconteceu com muita intensidade e logo depois foi pedido para que elas falassem um pouco de toda a frustração que passaram por meio do teatro, momento pelo qual um das educadoras disse que muitas vezes o planejamento não sai conforme é programado, a estagiária não colabora como necessário, as crianças não ouvem, os pais não entendem, a diretora cobra de mais, sempre tem alguma coisa pra fazer. Enfim elas conseguiram colocar tanto no teatro e quanto nas falas, todas as frustrações vivenciadas cotidianamente.

No encerramento foi questionado a elas, se é possível aprender e transformar a frustração em algo bom, quando todas concordaram que sim; assim visando um fechamento da atividade de forma lúdica e prazerosa; foi entregue em seguida uma vasilhinha especialmente confeccionada e enfeitada para elas, com feijão tropeiro, que representava a frustração elaborada. Com o texto reflexivo - Pensei que era sorvete...era feijão, deixando em evidências as escolhas que podem ser feitas até mesmo nas frustrações.

No oitavo encontro o objetivo era realizar junto com elas uma retrospectiva do crescimento profissional de cada uma até os dias atuais, enfatizando a importância de perceber as mudanças e melhorias enquanto professoras, separando em três momentos: passado, presente e futuro. A sala foi dividida com fita no chão, em três espaços considerando estes tempos.

Quando as professoras chegaram, as estagiárias falaram sobre o tema daquele encontro que seria sobre o crescimento profissional, que durante todo este tempo tivemos a oportunidade de vivenciar vários temas e que era importante também poder observar tudo o que foi construído até chegar as profissionais que são hoje. 
A maioria das educadoras levaram coisas de casa conforme solicitado com antecedência, somente duas delas que não levaram, porém, participaram normalmente. Foi explicado que aqueles itens representavam suas vidas profissionais e que algumas haviam levado coisas mais pessoais, mas que não deixavam de acrescentar no crescimento profissional. E que cada uma deveria deixar um objeto em um dos espaços das fitas que estavam no centro da sala.

Cada participante uma por uma se levantou e colocou os objetos no local indicado, sendo que também uma caixa cheia de itens ficou à disposição delas caso quisessem pegar algum outro objeto. Posteriormente foi perguntado a elas o que aqueles objetos representavam e o que elas sentiram quando passaram por cada momento, segue abaixo os itens e o que eles significavam conforme relatos:

Participante 3:

Passado: Bicicleta e um livro; que sempre foi para a escola/faculdade de bicicleta, sempre gostou muito de estudar.

Presente: Computador e caderno de planejamento; que simbolizam, as ferramentas que mais utiliza no seu dia a dia.

Futuro: Ela contando histórias, conversando com as crianças; que pretende continuar na profissão e aprender mais.

Participante 1:

Passado: uma apostila e algumas moedas; tempos difíceis da faculdade, em que se tinha que economizar muito para ter as moedinhas do xérox.

Presente: uma camiseta da formatura, que estava escrito atrás SOU PEDAGOGA e na frente EU VENCI; que foi um presente de uma professora madrinha da turma. E diz que hoje ela é pedagoga e que no tempo de faculdade passava muita vontade de comer pastel, se sentia perdida, foi um tempo muito difícil.

Futuro: um chaveiro de carrinho de bebê; que representa o filho que quer ter, e que quer usar seus conhecimentos também na educação do filho e em favor dele.

Participante 7:

Passado: convite de formatura; que simboliza o período de faculdade.

Presente: coração das habilidades; as habilidades que foi desenvolvendo com a equipe.

Futuro: foto da família; o futuro e a profissão que quer dar aos filhos.

Participante 4:

Passado: lápis; que não foi exatamente o curso que gostaria de ter feito, mais que com o passar do tempo foi gostando.

Presente: Bonequinho com um celular; que é um dos objetos que utiliza para pesquisa, para buscar formas diferente de dar aula.

Futuro: livro; representando os estudos e o aprender.

Participante 5:

Rev. Psicol Saúde e Debate. Set., 2020:6(2): 118-134. 
Passado: apostila; sobre a faculdade, que enfrentou o patrão, que teve que fazer escolhas e renúncias.

Presente: caderno de planejamento; hoje o quanto melhorou e o quanto é feliz sendo profissional.

Futuro: não levou nenhum objeto; mas que pretendia crescer muito, estudar e melhorar como educadora.

Participante 6:

Passado: canudo de formatura; representava a formatura em história, que foi a única que quis estudar na sua casa. E que decidiu mesmo que duvidando da sua própria capacidade. Mas que viu que conseguia.

Presente: uma bonequinha; representava as crianças, e que gosta do que faz, que não é fácil, mas é bom quanto tem retorno, se vê capaz.

Futuro: livro do pequeno príncipe; que é um livro que ama, e que já leu várias vezes e que sempre aprende algo novo, simbolizando que quer buscar mais conhecimento, quer aprender mais.

Participante 8:

Passado: lápis; que simboliza a sua paixão, que é a profissão. Relata que veio da roça para a cidade para estudar e que morou sozinha, conseguiu emprego em uma loja como vendedora, que foi muito difícil. Mas que foi muito bom, que ama o que faz, que não tem nada pesado na profissão.

Presente: super-mário na escadinha; da vontade de crescer e o do já conquistou.

Futuro: uma bonequinha; representa os filhos que pretende ter.

A participante 8 pontuou o que aprendeu e que aprende muito, se emocionou muito apontando o que aprende com cada educadora e inclusive com a gente, que tivemos a iniciativa do projeto. Disse que cresceu muito, que o projeto fez com que todas no grupo lidassem melhor com o que acontece no dia a dia de um CMEI.

E conforme a proposta, foi colocado em pauta que na vida profissional sobe-se degraus de aprendizados e alguns podem ser mais difíceis que outros, mas que existe a possibilidade de pedir ajuda uns aos outros e aprender mutuamente. Foi retratado que é importante reconhecer o lugar que se ocupa, como foi o processo de crescimento profissional e quanto é válido aprender com o outro através de suas experiências.

No fechamento do encontro foi dito que quando existe no ambiente de trabalho disposição de aprender e ensinar, cria-se oportunidades de crescimentos e as resoluções dos problemas ocorrem com mais facilidade. Até o presente momento muitos sentimentos já haviam sido mobilizados, a equipe se interagia melhor e optamos por trabalhar o tema Afeto e interação no trabalho na próxima atividade. 
No nono encontro, o ambiente foi organizado com duas mesas e quatro cadeiras cada, assim que o grupo estava completo foi explicado sobre o tema - com o tema afeto e interação no trabalho, sendo explicitado que afeto é a disposição de alguém por alguma coisa, seja positiva ou negativa. Logo após ter sido entregue folhas em branco, canetinhas, lápis de cor e borracha, foi explicado que elas deveriam, em forma de desenhos, poemas ou frases, expressar o relacionamento entre elas no ambiente de trabalho e o que mais as incomodavam.

Com o término dos desenhos foi entregue a seguinte frase, " A maioria das pessoas falam e fazem coisas sem consciência de como isso pode estar atingindo os outros. Não por egocentrismo, mas porque vivemos num mundo em que cada um tem que cuidar de si mesmo, nossa sociedade impõe essa forma de sobrevivência" da autora Léa Waider.

Em seguida foi solicitado que elas comentassem sobre a frase e os desenhos. Uma das educadoras fez cinco bonequinhas dando as mãos, representado a união, mas também fez uma chuva; que segundo ela representa as dificuldades que o grupo possui. Outra educadora também desenhou bonequinhas unidas, mas representando as funcionárias do turno em que trabalha justificando que possui maior contato com elas. Em geral o que prevaleceu nos desenhos foi a união entre o grupo que foi representada de várias formas, somente uma das educadoras não fez o desenho e ela também não comentou sobre o poema, aceitamos sua opção e seguimos para a próxima dinâmica.

Foi passada entre elas uma caixinha que continha palavras de afeto, quando elas deveriam escolher uma, mas sem revelar qual era a palavra, assim que todas escolherem foi comunicado que as palavras deveriam ser entregues a outra pessoa. Observando que a maioria escolheu o afeto acreditando que era para si, houve queixas, mas as educadoras aceitaram a proposta. Foi levantada a questão de que no cotidiano é preciso tolerância, respeito e que sem afeto isso não é possível, diante disso foi pedido para que elas entregassem as palavras uma para as outras; e surpreendentemente algumas educadoras dividiram a palavra ao meio. Uma das educadoras que era presente tanto no período matutino quanto no vespertino quase recebeu dois afetos.

Para o décimo e último encontro, foi confeccionado por nós uma linha do tempo no corredor de acesso à sala com todos os temas e frases trabalhadas em cada atividade, enfeitados em forma de um trem com vagões e frases ditas por elas. Representamos também com algumas imagens postas sobre o chão, colocamos várias carinhas com expressões faciais diferentes e que se referiam as várias sensações e emoções despertadas durante o projeto.

Ao iniciar elas foram convidadas a fazer uma fila e foi dito a elas:

-Faremos uma viagem de trem da vida profissional, apertem os cintos e apreciem a paisagem! Cantando a música do trem adaptada - "Eu vou andar de trem, você vai também, só falta comprar passagem, passagem para o velho trem" as educadoras foram conduzidas a ir se movimentando pelo corredor em direção à sala, sendo que durante todo o caminho foram colados Rev. Psicol Saúde e Debate. Set., 2020:6(2): 118-134. 
no chão emojis com várias expressões faciais; simbolizando as emoções e vivências do grupo até o presente momento.

Ao chegar de frente a sala a representação do trem em EVA, estava disposto na parede e ali iniciou-se uma discussão dos temas mais marcantes vivenciados pelo grupo; tais como: trabalhando identidade, frustrações. Logo após foi lido a frase que estava na porta: Sejam bemvindas, faremos uma pausa, fiquem à vontade.

Quando as professoras entraram na sala, uma das estagiárias estava cantando a música aquarela, do cantor Toquinho, que se refere aos inícios escolares, a pedagogia e aos aprendizados. As cadeiras estavam dispostas em círculo, sendo que debaixo de uma delas estava uma premiação, um vale pote de sorvete; a ser compartilhado no momento do encerramento.

Logo após todas se acomodarem foi dito o seguinte:

Bom dia! Gostaríamos de pegar a passagem de vocês, a boneca. Vamos carimbar a boneca e pediremos para que falem sobre o a experiência de terem participado do projeto; emoções, sentimentos, frustrações, mudanças, aprendizado que foram despertados (feedback) e porque enfeitaram a boneca dessa maneira.

Este momento do feedback foi muito rico e significativo, pois as estagiárias tiveram a oportunidade de no dia do encerramento receber de todas as educadoras o feedback do trabalho, e foi um feedback muito positivo. Pois nos relatos elas disseram que a equipe passou a trabalhar melhor, buscaram entender mais umas às outras e perceberam que a frustração chega para todas, mas que juntas elas poderiam melhorar e se ajudarem.

As educadoras pontuaram também, que o projeto auxiliou elas a lidarem melhor com as emoções e desafios apresentados no cotidiano do trabalho, na convivência da equipe, na maneira de enxergar o outro, na desconstrução de medos, inseguranças e pré-conceitos. Evidenciaram que tudo isso contribuiu para que se conhecessem mais enquanto pessoas e profissionais, bem como, foi reiterado o desejo para que o projeto tivesse continuidade.

A diretora do $\mathrm{CMEI}$, esteve presente e prestou uma belíssima homenagem as estagiárias e a nossa orientadora do Projeto MIP, quando as mesmas foram agraciadas com 0 reconhecimento do trabalho desenvolvido. Fomos todas presenteadas pela diretora e pelas professoras com um vaso de orquídeas com falas de reiterados agradecimentos da contribuição do projeto, pela iniciativa e empenho na promoção de saúde no trabalho e de diálogos e relações mais produtivas e saudáveis entre toda a equipe no âmbito escolar.

A orientadora do Projeto de Intervenção - MIP, também participou do encerramento das atividades, quando fez suas colocações acrescentando com seu profissionalismo e delicadeza; agradeceu imensamente o espaço que foi concedido pela direção da escola para realização do trabalho e a abertura das professoras de aceitarem participarem do projeto. E em diversos momentos se emocionou diante das falas das professoras da educação infantil, sendo confirmado Rev. Psicol Saúde e Debate. Set., 2020:6(2): 118-134. 
o alcance do objetivo geral proposto: utilizar o brincar como estratégia, intervenção e promoção de saúde no trabalho para as professoras da Educação Infantil do Centro Educacional Municipal Infantil (CMEI) Vovó Chiquinha, da Prefeitura Municipal de Patos de Minas.

As estagiárias agradeceram pela oportunidade e disponibilidade tanto da Escola quanto das professoras, e foi ressaltados o seguinte:

A boneca representa vocês como profissionais, como vestem e alimentam a vida profissional: investimentos, estudos, dedicação. E como essa viagem não termina aqui de fato, somente o projeto. Sigam com a passagem de vocês em mãos para fazerem outras paradas na vida, para aprenderem, para ensinarem.

E foi prestada uma homenagem singela pelas estagiárias a cada educadora e a diretora, porém preparada com muito carinho e em agradecimento a todas da equipe; com bombons e uma mensagem de reflexão, pois sem a disponibilidade das mesmas, o trabalho não seria possível. E também `a orientadora, que se atentou para a finalidade e apontou os caminhos para uma melhor condução do projeto, interviu quando necessário e acreditou no mesmo.

Diante do que foi descrito acredita-se que os objetivos foram alcançados e a proposta realizada, com criterioso compromisso - ética e responsabilidade.

\section{CONSIDERAÇÕES}

Constata-se que o projeto contribuiu para um olhar mais humanizado e compreensivo junto a equipe de trabalho, gerando um ambiente mais leve para o desenvolvimento das funções laborais e com maior comunicação e entendimento em prol da saúde nesse contexto. Por meio das demandas trazidas e observadas nos encontros, pode-se promover e intervir de forma saudável e respeitosa sobre as necessidades de se repensar e reavaliar as práticas educativas; com recursos e ferramentas que são utilizados no cotidiano das profissionais incentivou-se resgate da identidade e potencialidades das educadoras da educação Infantil.

Observando todos os relatos acima e as intervenções realizadas na execução do projeto, evidencia-se que este agregou ao estudante de psicologia maiores conhecimentos e motivações para a busca por novos aprendizados nos diferentes contextos de atuação; como na mediação entre Educação e Psicologia que pudemos vivenciar. Bem como, a importância de se levar a reflexão das relações interpessoais e habilidades sociais nas atividades laborais, pois a Psicologia está presente dentro das escolas não somente voltada ao aluno, mas também a comunidade necessita de educadores capacitados; que saibam trabalhar em equipe, engajados, comprometidos com a saúde psicoemocional e física para estarem em sala de aula.

Por último, fechamos esse Relato de Experiência com a convidativa reflexão: "Brincar... não é perder tempo, é ganha-lo..", de Carlos Drummond de Andrade. Brincando seriamente num 
sentido pedagógico e acadêmico, nos sentimos também nos movimentando dentro de uma roda gigante - a roda da vida; cenário de aprendizados e conquistas de conhecimentos em que pudemos transpor desejos e motivações em prol da realização de um Projeto muito especial. Através do brincar como intervenção e promoção de saúde no trabalho com professoras da educação infantil, todos os encontros possibilitaram experiências e vivências enriquecedoras; maior tempo de conhecimento, afeto, interação e respeito às diferenças entre as educadoras, maior disponibilidade para trocas e espírito coletivo, alcançando assim, os objetivos propostos.

\section{REFERÊNCIAS}

Alencar, E. S.; Oliveira, M. S. (2017). História da educação infantil no brasil: as brincadeiras e os jogos. Perspec. Dial.: Rev. Educ. e Soc., Naviraí, v. 4, n. 7, p. 51-63.

Dejours, C. (1987). A Loucura do Trabalho: Estudo de Psicopatologia do Trabalho. São Paulo: Cortez.

Freire, R. P.Freire; Garcia M. B. (2011). O brincar como recurso terapêutico para o adulto maior institucionalizado: uma proposta de intervenção em terapia ocupacional. Estud. interdiscipl. envelhec., Porto Alegre, v. 16.

Freud, S. (2006). Escritores criativos e devaneio. Edição standard brasileira das obras psicológicas completas de Sigmund Freud. Rio de Janeiro: Imago. (Original Publicado em 1908). Vol. IX. p.135-143.

Malvestiti, R.; Maas, L.; Gontijo, L. A. (2017). A sobrecarga mental de trabalho como um fator desencadeador do estresse ocupacional em educadores infantis. Espacios, v. 38, n.45.

Santos, S. M. P. dos; Cruz, D. R. M. (1997). O lúdico na formação do educador. In: . (Org.). O lúdico na formação do educador. Petrópolis: Vozes.

Kishimoto, T. M. (2017). Jogo, brinquedo, brincadeira e a educação. São Paulo-SP: Cortez Editora. 